\title{
Expectation Enhances the Regional Brain Metabolic and the Reinforcing Effects of Stimulants in Cocaine Abusers
}

\author{
Nora D. Volkow, ${ }^{1,3}$ Gene-Jack Wang, ${ }^{1}$ Yemin Ma, ${ }^{1}$ Joanna S. Fowler, ${ }^{2}$ Wei Zhu, ${ }^{4}$ Laurence Maynard, ${ }^{1}$ Frank Telang, ${ }^{1}$ \\ Paul Vaska, ${ }^{1}$ Yu-Shin Ding, ${ }^{2}$ Christopher Wong, ${ }^{1}$ and James M. Swanson ${ }^{5}$ \\ ${ }^{1}$ Medical and ${ }^{2}$ Chemistry Departments, Brookhaven National Laboratory, Upton, New York 11973, Departments of ${ }^{3}$ Psychiatry and ${ }^{4}$ Applied Mathematics, \\ State University of New York at Stony Brook, Stony Brook, New York 11794, and ${ }^{5}$ University of California at Irvine, Child Development Center, Irvine, \\ California 92612
}

The reinforcing effects of drugs of abuse result from the complex interaction between pharmacological effects and conditioned responses. Here we evaluate how expectation affects the response to the stimulant drug methylphenidate in 25 cocaine abusers. The effects of methylphenidate $\left(0.5 \mathrm{mg} / \mathrm{kg}\right.$, i.v.) on brain glucose metabolism (measured by $\left[{ }^{18} \mathrm{~F}\right]$ deoxyglucose-positron emission tomography) and on its reinforcing effects (self-reports of drug effects) were evaluated in four conditions: (1) expecting placebo and receiving placebo; (2) expecting placebo and receiving methylphenidate; (3) expecting methylphenidate and receiving methylphenidate; (4) expecting methylphenidate and receiving placebo. Methylphenidate increased brain glucose metabolism, and the largest changes were in cerebellum, occipital cortex, and thalamus. The increases in metabolism were $\sim 50 \%$ larger when methylphenidate was expected than when it was not, and these differences were significant in cerebellum (vermis) and thalamus. In contrast, unexpected methylphenidate induced greater increases in left lateral orbitofrontal cortex than when it was expected. Methylphenidate-induced increases in self-reports of "high" were also $\sim 50 \%$ greater when subjects expected to receive it than when they did not and were significantly correlated with the metabolic increases in thalamus but not in cerebellum. These findings provide evidence that expectation amplifies the effects of methylphenidate in brain and its reinforcing effects. They also suggest that the thalamus, a region involved with conditioned responses, may mediate the enhancement of the reinforcing effects of methylphenidate by expectation and that the orbitofrontal cortex mediates the response to unexpected reinforcement. The enhanced cerebellar activation with expectation may reflect conditioned responses that are not linked to conscious responses.

Key words: imaging; cerebellum; FDG; addiction; context; dopamine; reinforcement; conditioned responses

\section{Introduction}

The reinforcing effects of drugs of abuse are a result of complex interactions between pharmacological effects and conditioned responses (Robinson and Berridge, 1993). These nonpharmacological variables shape the expectation of the drug effects, which in turn modulates the responses to the drug (Mitchell et al., 1996). For example, in drug abusers, the subjective responses to the drug are more pleasurable when subjects expect to receive the drug than when they do not (Kirk et al., 1998).

The effects of expectation on brain responses to drugs of abuse have been studied in laboratory animals. For example, cocaineinduced increases in dopamine (DA) in nucleus accumbens (NAc), an effect associated with its reinforcing value (Di Chiara and Imperato, 1988), is larger when animals are given cocaine in an environment in which they had previously received it than in a novel environment (Duvauchelle et al., 2000) or when animals self-administer cocaine than when cocaine administration is in-

\footnotetext{
Received July 21, 2003; revised 0ct. 14, 2003; accepted 0ct. 14, 2003.

This research was supported in part by the Department of Energy (Office of Biological and Environmental Research) (DE-AC02-98CH10886) and the National Institute on Drug Abuse (DA 7092-01 and DA00280).

Correspondence should be addressed to Dr. Nora D. Volkow, National Institute on Drug Abuse, 6001 Executive Boulevard, Room 5274, Rockville, MD 20853. E-mail: nvolkow@nida.nih.gov.

Copyright $\odot 2003$ Society for Neuroscience $\quad 0270-6474 / 03 / 2311461-08 \$ 15.00 / 0$
}

voluntary (Hemby et al., 1997). Also, cocaine-induced changes in regional brain metabolism, which are an indicator of brain function (Sokoloff et al., 1977), are different when animals selfadminister cocaine from when administration is involuntary (Graham and Porrino, 1995) and when cocaine is given in a conditioned environment versus their home cage (Knapp et al., 2002).

Not all studies, however, have shown that expectation enhances responses to a reinforcer. Indeed, there is evidence that for natural reinforcers, expected rewards do not induce activation of DA cells or of cells in orbitofrontal cortex (OFC), whereas unexpected rewards do (Schultz et al., 1998, 2000). Similarly, imaging studies in humans have documented that for natural reinforcers unpredictable reward induced larger activation than predictable reward in NAc and OFC (Berns et al., 2001).

The effects of expectation on the response of the human brain to drugs of abuse have not been reported. Here we assessed the effects of expectation on the regional brain metabolic responses induced by intravenous methylphenidate (MP) in cocaine abusers. We measured brain metabolism rather than changes in DA because it allows one to evaluate the brain response to the drug, which includes primary sites of action as well as downstream effects. Brain metabolism was measured with positron emission 


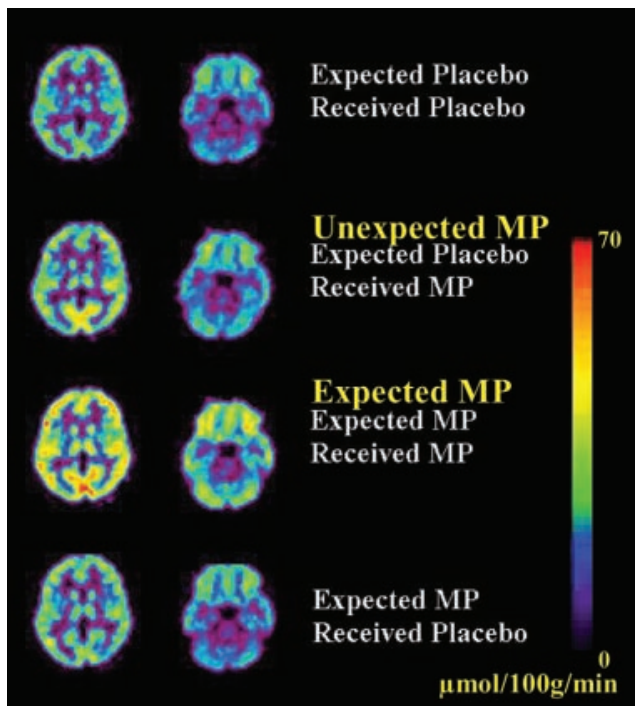

Figure 1. Brain metabolic images at the thalamic and cerebellar levels for the four conditions: (1) expected placebo received placebo, (2) expected placebo received MP, (3) expected $M P$ received MP, and (4) expected MP received placebo. Scale is to the right and reflects micromoles/100 gm per minute. Note the larger increases in metabolism when MP was expected than when it was not expected.

tomography (PET) and $\left[{ }^{18} \mathrm{~F}\right]$ deoxyglucose (FDG). For studies using FDG, we decided to use MP because it is pharmacologically similar to cocaine but has more favorable brain pharmacokinetic properties. Both drugs block DA transporters (DATs) with similar potencies (Volkow et al., 1995), and cocaine abusers report that the effects of intravenous MP are similar to those of cocaine (Wang et al., 1997). DAT blockade, however, is much longer for MP (half-life $90 \mathrm{~min}$ ) than for cocaine (20 min), which is shorter than the interval evaluated by FDG (30 min). The effects of MP were measured when cocaine abusers were expecting as well as when they were not expecting to receive the drug. We hypothesized that the reinforcing effects of MP would be enhanced by expectation and that this would be paralleled by an enhanced activation of brain regions involved in its reinforcing effects.

\section{Materials and Methods}

Subjects. Twenty-five active cocaine abusers (21 male and 4 female; $41 \pm$ 3 years of age) who responded to an advertisement were studied. Subjects fulfilled Diagnostic and Statistical Manual, Version IV of the American Psychiatric Association criteria for cocaine dependence and were active users for at least the previous 6 months (free-base or crack at least " $4 \mathrm{gm}$ " per week). Exclusion criteria included current or past psychiatric disease other than cocaine dependence; past or present history of neurological, cardiovascular, or endocrinological disease; history of head trauma with loss of consciousness $>30 \mathrm{~min}$; and current medical illness and drug dependence other than for cocaine or nicotine. Subjects had an average history of $13 \pm 5$ years of cocaine use. Written informed consent was obtained from all subjects after complete description of the study and following the guidelines set by the Institutional Review Board at Brookhaven National Laboratory.

Scans. PET scans were acquired on a whole-body, high-resolution positron emission tomograph (Siemens High Resolution + , with $4.6 \times$ $4.6 \times 4.2 \mathrm{~mm}$ resolution at center of field of view and 63 slices) in three-dimensional dynamic acquisition mode using FDG. Methods for positioning of subjects, catheterizations, transmission scans, and blood sampling and analysis have been published (Wang et al., 1992). Briefly, a 20 min emission scan was started $35 \mathrm{~min}$ after injection of $4-6 \mathrm{mCi}$ of FDG. Arterialized blood sampling was used to measure FDG in plasma. During the study, subjects were positioned supine in the PET camera with their eyes open; the room was dimly lit, and noise was kept to a minimum except for the periodic evaluation of drug effects.

Subjects were scanned on 4 different days with FDG under the four conditions defined by the expectation-by-drug combinations: (1) expecting placebo and receiving placebo (PL/PL; baseline); (2) expecting placebo and receiving MP (PL/MP; drug effects without expectation); (3) expecting MP and receiving MP (MP/MP; drug effects with expectation); (4) expecting MP and receiving placebo (MP/PL; expectation effects alone). The order of the conditions was randomized across subjects. Placebo (3 cc of saline) or MP ( $0.5 \mathrm{mg} / \mathrm{kg}$, i.v. $)$ was injected over $60 \mathrm{sec}$ and $1 \mathrm{~min}$ before FDG injection. The plasma concentrations of MP were measured before and at 10, 25, 40, and 54 min after MP using capillary gas chromatography/mass spectrometry (Srinivas et al., 1991).

Behavioral measures. Behavioral effects were evaluated using analog scales that assessed self-reports of "high," "drug effects," "alertness," and "restlessness" from 0 (felt nothing) to 10 (felt intensely) (Wang et al., 1997). These self-reports of drug effects have been shown to be reliable and consistent across studies and to predict administration of drugs in human subjects (Fischman and Foltin, 1991). Subjective ratings were recorded $5 \mathrm{~min}$ before placebo or MP and then every minute for the first $20 \mathrm{~min}$ and at 25,30,45, and $67 \mathrm{~min}$ after administration. At the end of the study, subjects were asked to rate drug liking (1-10).

Analysis. The data were analyzed using statistical parametric mapping (SPM) (Friston et al., 1995), and the results were corroborated with manually drawn regions of interest (ROI). For the SPM analyses, the images were spatially normalized using the template provided in the SPM 99 package and then normalized to the mean metabolic activity for the whole brain (mean of all voxels within the brain) and subsequently smoothed with a $16 \mathrm{~mm}$ isotropic Gaussian kernel. Paired samples $t$ tests were performed for the following four planned but nonorthogonal comparisons: drug effects when unexpected (PL/PL vs PL/MP) and drug effects when expected (PL/PL vs MP/MP); effects of expectation on MP (PL/MP vs MP/MP); and effects of expectation alone (PL/PL vs MP/PL). Significance was set at $p<0.005$, and the statistical maps were overlaid on a structural image derived from magnetic resonance imaging (MRI). Because of incomplete sampling in the upper brain levels, we were unable to do the spatial normalization in 2 of the subjects, and thus the SPM results reflect the analysis done in 23 subjects.

In addition to assessing the differences in the magnitude of metabolic activation, we also assessed the differences in the volumes that were activated by MP when it was unexpected (PL/MP) versus when it was expected (MP/MP). Although SPM provides activation volumes, it does not provide statistical tests to compare the differences in activation volumes between two conditions. For this purpose we applied the statistical resampling strategy using the jackknife method (Quenouille, 1956; Miller, 1974; Efron, 1982). The following procedures were performed. (1) The SPM maps for activation for unexpected MP (PL/PL vs PL/MP) and expected MP (PL/PL vs MP/MP) comparisons were obtained with all of the subjects $(n=23)$. (2) One at a time, each subject was taken out and the same SPM analyses were repeated using the remaining 22 subjects. (3) Pseudo values were generated using all of the SPM activation volumes generated in the previous jackknife procedures. These pseudo values are independent estimates of the activation volumes at the significance level of $p<0.005$ (Miller, 1974). (4) Paired sample $t$ tests were performed on the pseudo values to compare the activation volumes with unexpected versus expected MP within those brain regions identified by significant differences in magnitude of activation. The volumes of activations were expressed as a percentage of the activation of a given anatomical region as defined from the Talairach Daemon (Lancaster et al., 2000). We chose $p<0.005$ rather than $p<0.001$ because we wanted to avoid false negatives, and our design retested the SPM findings with the ROI method.

For the ROI analysis a template was used (Wang et al., 1992) that locates 114 ROI. We averaged the values from the ROI from the different slices corresponding to the same anatomical region into 10 "composite" brain regions including that for whole brain (average of metabolism in all slices). We compressed the original template into 10 regions to increase the precision of our measures and decrease the multiplicity of comparisons. The errors on measurements of small regions from PET images are large because of the limited spatial resolution of PET (Bendriem et al., 


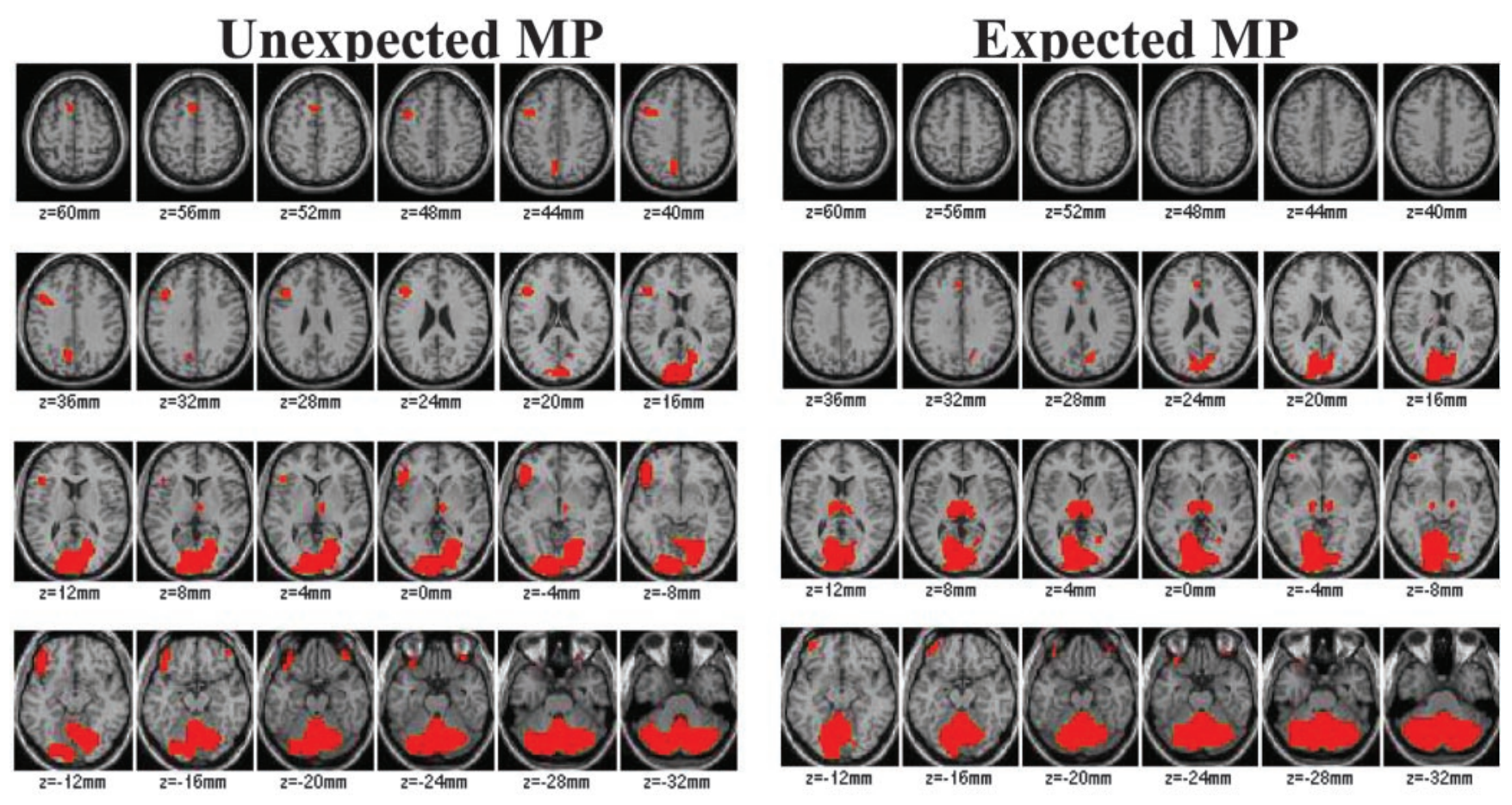

Figure 2. Brain maps obtained with SPM after normalization for the global metabolic increases to reveal the areas where MP induced the largest increases in metabolism both for unexpected and expected MP (areas in red). Comparisons are with the "expected placebo received placebo" condition, and significance was set at $p<0.005$. Note that the largest increases with MP occurred in cerebellum, occipital cortex, and thalamus. Note also the much larger areas of activation in thalamus for expected MP and in lateral orbitofrontal cortex for unexpected MP.

Table 1. Location of the center of the areas in which MP induced significant increases $(p<0.005$; cluster size $>100$ pixels) in relative metabolic activity with respect to the $x, y, z$ coordinates of the Talairach space and magnitude of the effects as assessed by the $T$ values when MP was unexpected (PL/MP) and when it was expected (MP/MP)

\begin{tabular}{|c|c|c|c|c|c|c|c|c|}
\hline & \multicolumn{4}{|c|}{ Unexpected MP (PL/MP) } & \multicolumn{4}{|c|}{ Expected MP (MP/MP) } \\
\hline & $x$ & $y$ & $z$ & $T$ & $x$ & $y$ & $z$ & $T$ \\
\hline \multicolumn{9}{|l|}{ Frontal lobe } \\
\hline Left inferior gyrus & -45 & 27 & -13 & 3.59 & & & & NS \\
\hline Left anterior cingulate & & & & NS & -5 & 31 & 25 & 3.41 \\
\hline \multicolumn{9}{|l|}{ Occipital lobe } \\
\hline Right lingual gyrus & 19 & -79 & -9 & 4.51 & 11 & -87 & 5 & 3.96 \\
\hline Left lingual gyrus & -7 & -89 & -9 & 4.23 & -11 & -89 & 5 & 4.78 \\
\hline Thalamus & & & & NS & -11 & -19 & 5 & 4.64 \\
\hline \multicolumn{9}{|l|}{ Cerebellum } \\
\hline Right vermis & 17 & -63 & -33 & 8.29 & 3 & -63 & -29 & 13.17 \\
\hline Left vermis & -15 & -63 & -33 & 6.78 & -7 & -63 & -29 & 9.0 \\
\hline
\end{tabular}

1991) and the imprecision in locating a "functionally distinct" area in the brain, the location of which is likely to vary among individuals (Rademacher et al., 2001). A repeated measures ANOVA was used to identify the ROI that differed between conditions, and then post hoc $t$ tests were used to determine for which of the conditions the differences were significant.

Pearson product moment correlations were used to assess the association between the regional metabolic changes that differed between the unexpected and expected MP conditions (expressed as a percentage of change from the PL/PL condition) and MP-induced behavioral effects both for the expected and the unexpected conditions.

\section{Results}

Effects of MP on regional brain metabolism

Plasma MP concentrations did not differ for the unexpected (PL/ $\mathrm{MP})$ or the expected MP (MP/MP) conditions and at $10 \mathrm{~min}$ reached an average concentration of $158 \mathrm{ng} / \mathrm{ml}$ and at $25 \mathrm{~min}$ of $97 \mathrm{ng} / \mathrm{ml}$ for both conditions. MP significantly increased wholebrain glucose metabolism compared with the baseline condition (PL/PL) when it was both unexpected $(2.9 \pm 2.5 \mu \mathrm{mol} / 100 \mathrm{gm}$ per minute; $t=5.9$; df $24 ; p<0.0001)$ and expected $(4.2 \pm 5.4$ $\mu \mathrm{mol} / 100$ gm per minute; $t=3.8 ; \mathrm{df} 24 ; p<0.001)$. The increase was $\sim 50 \%$ higher when MP was expected than when unexpected (13.6 \pm 17 vs $9.3 \pm 8 \%$ change). In contrast, the expectation effects when placebo $(\mathrm{MP} / \mathrm{PL})$ was received in the global $(0.2 \pm 3$ $\mu \mathrm{mol} / 100$ gm per minute; $1 \pm 1 \%$ change; NS) and regional metabolic measures were negligible (Fig. 1).

The results from SPM revealed that the largest increases from MP (expected and unexpected) occurred in cerebellum, occipital cortex, and thalamus (Fig. 2, Table 1).

In the SPM analysis, normalization for the global increases induced by MP results in the identification of "relative decreases" in those regions in which the increases are smaller than in the rest of the brain. Relative decreases after MP (expected and unexpected) occurred in limbic brain regions [ventral striatum (including nucleus accumbens), parahippocampal gyri (including amygdala), and insular cortex] and frontal regions (including medial orbitofrontal cortex) (Fig. 3, Table 2).

The SPM comparison between unexpected (PL/MP) versus 


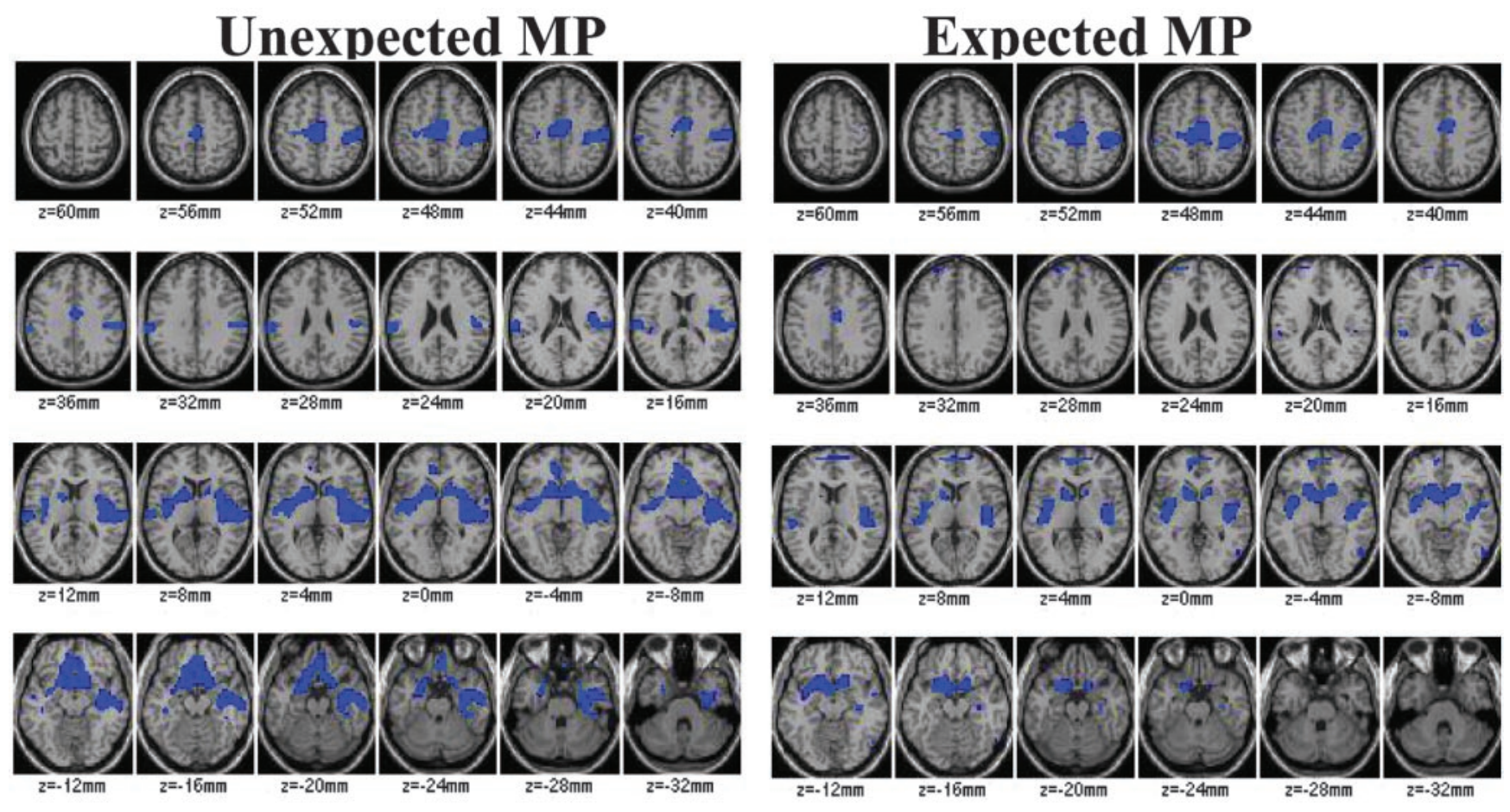

Figure 3. Brain maps obtained with SPM after normalization for the global metabolic increases to reveal the areas where MP induced relative decreases in metabolism for both unexpected and expected MP (areas in blue). Comparisons are with the expected placebo received placebo condition, and significance was set at $p<0.005$. Note the relative decreases for both conditions in limbic regions (NAc, Brodmann area 25, insula, amygdala) and in motor cortices.

Table 2. Location of the center of the areas in which MP induced significant decreases $(p<0.005$; cluster size $>100$ pixels) in relative metabolic activity with respect to the $x, y, z$ coordinates of the Talairach space and magnitude of the effects as assessed by the $T$ values when MP was unexpected (PL/MP) and when it was expected (MP/MP)

\begin{tabular}{|c|c|c|c|c|c|c|c|c|}
\hline & \multicolumn{4}{|c|}{ Unexpected MP (PL/MP) } & \multicolumn{4}{|c|}{ Expected MP (MP/MP) } \\
\hline & $x$ & $y$ & $z$ & $T$ & $x$ & $y$ & $z$ & $T$ \\
\hline \multicolumn{9}{|l|}{ Frontal lobe } \\
\hline Right medial gyrus & 11 & 19 & -17 & 3.53 & 13 & 11 & -17 & 3.83 \\
\hline Left medial gyrus & -11 & 27 & -17 & 3.46 & -9 & 13 & -17 & 4.84 \\
\hline Right rectal gyrus & 3 & 37 & -25 & 3.18 & & & & NS \\
\hline Left rectal gyrus & -5 & 27 & -21 & 2.96 & & & & NS \\
\hline Right subcallosal gyrus & 11 & 11 & -13 & 5.13 & 11 & 11 & -13 & 3.95 \\
\hline Left subcallosal gyrus & -5 & 7 & -13 & 4.52 & -9 & 11 & -13 & 5.91 \\
\hline Right anterior cingulate & 7 & 17 & -9 & 3.77 & 5 & 15 & -7 & 3.21 \\
\hline Left anterior cingulate & -7 & 19 & -9 & 3.7 & -3 & 11 & -7 & 3.96 \\
\hline Right subgyral & & & & NS & 13 & -15 & 43 & 3.59 \\
\hline Left subgyral & & & & NS & -13 & -23 & 43 & 3.34 \\
\hline \multicolumn{9}{|l|}{ Limbic lobe } \\
\hline Right cingulate gyrus & 5 & -7 & 35 & 3.59 & 7 & -11 & 41 & 4.72 \\
\hline Left cingulate gyrus & -1 & -11 & 41 & 5.45 & & & & NS \\
\hline Right insula & 39 & -7 & -5 & 4.55 & 43 & -15 & 3 & 5.81 \\
\hline Left insula & -39 & -7 & -5 & 3.8 & & & & NS \\
\hline Right parahippocampal & 31 & -15 & -20 & 4.35 & 35 & -19 & -15 & 3.14 \\
\hline Left parahippocampal & -25 & -5 & -20 & 3.26 & & & & NS \\
\hline Right ventral striatum & 15 & 11 & -5 & 4.76 & 11 & 11 & 1 & 3.81 \\
\hline Left ventral striatum & -17 & 11 & -5 & 3.66 & -9 & 13 & 1 & 3.98 \\
\hline \multicolumn{9}{|l|}{ Temporal lobe } \\
\hline Right middle temporal & 43 & -17 & -9 & 5.09 & 43 & -15 & -9 & 3.33 \\
\hline Left middle temporal & -43 & -9 & -9 & 3.02 & -37 & -9 & -9 & 3.51 \\
\hline
\end{tabular}

expected MP (MP/MP) showed significantly greater increases in the magnitude of the response in cerebellum (vermis) and thalamus for expected than unexpected MP (Fig. 4) and the opposite pattern (significantly greater increases for unexpected than expected MP) in left lateral OFC (Brodmann area 47) (Fig. 4).

The comparison of the volume of activation for these brain regions showed significantly larger areas of activation for ex- pected MP (MP/MP) when compared with unexpected MP (PL/ $\mathrm{MP}$ ) in vermis (26 vs $13 \%$; $t=2.5$; df $22 ; p<0.05$ ) and in thalamus (44 vs $5 \% ; t=3.9 ; \mathrm{p}<0.001$ ) and a larger area of activation for unexpected MP (PL/MP) when compared with expected MP (MP/MP) in left lateral OFC (Brodmann area 47) (11 vs $0.5 \% ; t=3.6 ; p=0.002$ ) (Fig. 4 ).

The ROI analyses corroborated that the magnitude of the MP- 

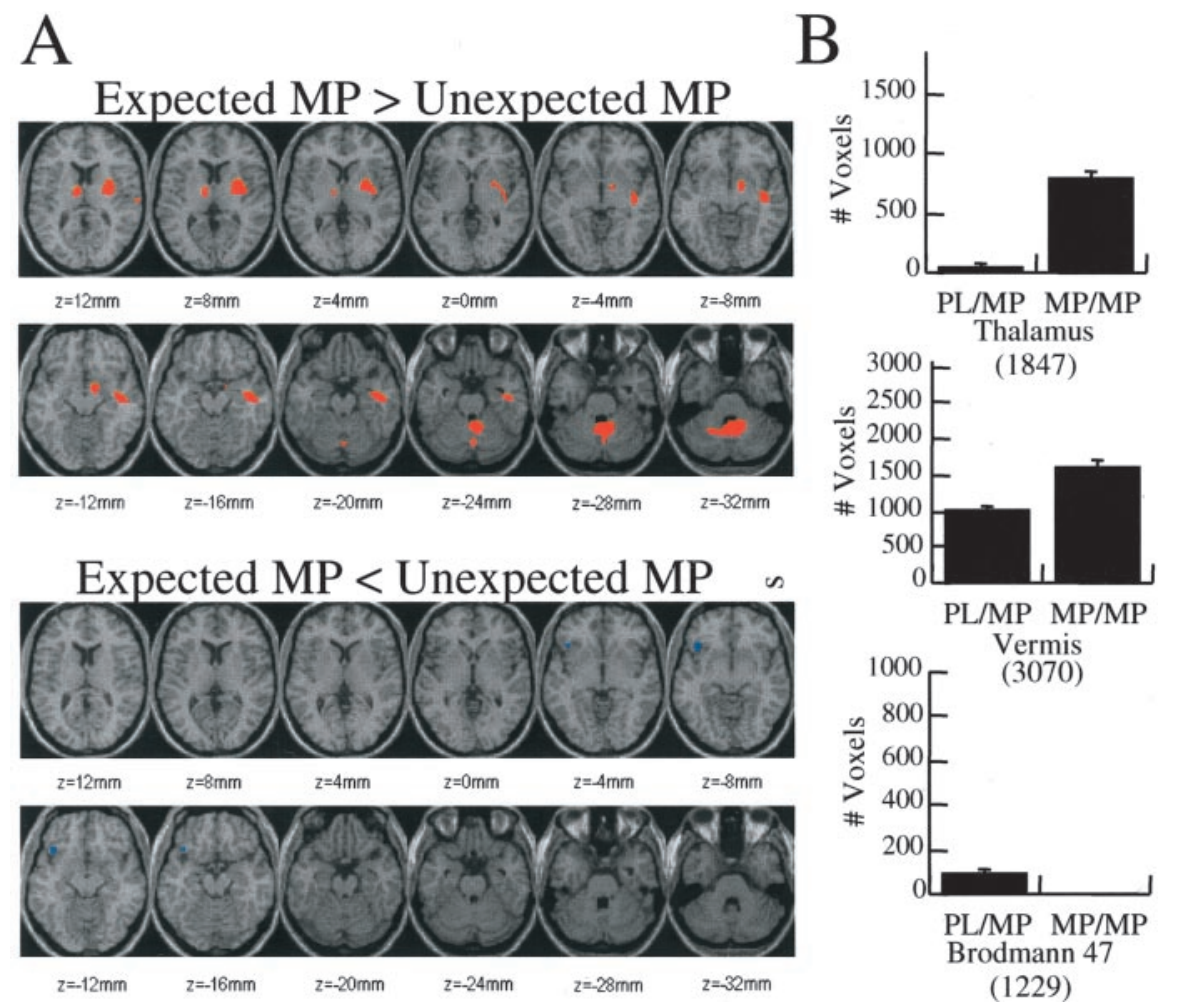

Figure 4. A, Brain maps obtained with SPM showing the areas where the increases were significantly larger for expected versus unexpected MP (areas in red) and where they were significantly smaller for expected than unexpected MP (areas in blue). Significance was set at $p<0.005$. B, Volumes of the areas of activation (number of pixels where activation was at the $p<0.005$ level) for thalamus, vermis, and Brodmann area 47 for unexpected and expected MP. The volumes were significantly larger for expected MP in thalamus $(p<0.001)$ and vermis $(p<0.05)$ and for unexpected MP in Brodmann area $47(p<0.002)$. The numbers within the parentheses correspond to the total number of pixels for each region and were used to establish the scale in the ordinate axis.

induced increases in metabolism were significantly higher for expected than for unexpected MP in thalamus $(12 \pm 11$ vs $19 \pm$ $14 \%$ increase in absolute metabolic measures; $t=7.6$; df $24 ; p<$ $0.05)$ and in cerebellar vermis $(11 \pm 7$ vs $19 \pm 16 \%$ increase in absolute metabolic measures; $t=7.8 ; p<0.05)$.

\section{Effects of expectation on the reinforcing effects of MP and} correlation with the metabolic measures

MP increased self-reports of "drug liking," "high," "feel drug," and "restlessness" (Fig. 5). The self-reports of high were significantly greater for MP when expected (4.8) than unexpected (3.1) (Fig. 5). Indeed, the high was $\sim 50 \%$ greater for expected than for unexpected MP. The high after placebo was low and did not differ whether subjects expected MP or not. A similar pattern occurred for the self-report of feel drug.

The increases in self-reports of high and drug liking were significantly correlated with the increases in metabolism induced by MP (unexpected and expected) in thalamus (Fig. 5) but not in vermis (data not shown). The correlations between metabolic rates and feel drug ratings were not significant (data not shown).

\section{Discussion}

\section{Effects of MP on regional brain metabolism}

Intravenous MP produced marked increases in whole-brain metabolism in cocaine abusers. This finding differs from a previous study that reported metabolic decreases after intravenous cocaine to cocaine abusers (London et al., 1990). Our design and methods may account for this difference. Both MP and cocaine have sim- ilar potencies in blocking DAT in the human brain (Volkow et al., 1999a), but they differ in their pharmacokinetics, with the half-life being much greater for MP than for cocaine (Volkow et al., 1995, 1996). Thus, during the $30 \mathrm{~min}$ uptake period of FDG, after cocaine the metabolic measures reflect the uptake and clearance from brain, whereas for MP they will reflect the uptake and plateau of the drug in brain.

The brain region most sensitive to $\mathrm{MP}$ effects regardless of condition was the cerebellum. We previously documented cerebellar activation after MP in controls (Volkow et al., 1997a) and in cocaine abusers (Volkow et al., 1999b). DAT density is low in cerebellum (Melchitzky and Lewis, 2000), so blockade of noradrenergic [norepinephrine (NE)] transporters by MP (Patrick et al., 1987) may have contributed to the metabolic increases in this brain region that receives a dense NE innervation (Reznikoff et al., 1986); however, it could also reflect downstream effects from DA stimulation of striatum, which sends projections to cerebellum (Hook and Wise, 1995). Indeed, we showed previously that striatal DA D2 receptor availability predicted MP-induced increases in cerebellar metabolism (Volkow et al., 1997a,b). Although one could question why metabolic increases did not occur in striatum, this is likely to reflect the fact that metabolism predominantly reflects activity in nerve terminals and not cell bodies (Schwartz et al., 1979). MP by blocking DAT targets GABAergic cells in striatum, and thus metabolic changes are to be expected in regions where these projections terminate.

After controlling for "global" increases induced by MP, the SPM analyses revealed relative decreases in limbic regions that are part of brain reward circuits (ventral striatum, Brodmann area 25, insula, amygdala) (Schultz et al., 1998). This finding contrasts with increases in limbic regions reported after intravenous cocaine with functional MRI (fMRI) (Breiter et al., 1997), although more recent studies with $\mathrm{fMRI}$ have also reported decreases in limbic regions after intravenous MP (Dirckx et al., 2003). Nonetheless, extrapolation of fMRI and PET-FDG is difficult because the temporal resolution of these two techniques differs ( $30 \mathrm{~min}$ to measure metabolism with PET-FDG and 2-5 min to measure the peak blood oxygenation level dependent signal with fMRI) (Volkow et al. 1997b). The higher temporal resolution of fMRI than that of PET-FDG corresponds better to the short duration of the high $(\sim 10 \mathrm{~min})$, and its ability to do continuous brain measurements allows one to assess the correspondence between the pharmacokinetics of the drug and the temporal course of its behavioral effects. Thus metabolic changes measured by PETFDG reflect not only the neural changes associated with the high but also its aftereffects. Therefore, decreases in "relative metabolism" could reflect decreases, increases that were lower than those for the rest of the brain, or short-duration increases followed by decreases. Regardless, these results document that the reward circuit responds to intravenous MP differently than the rest of the brain. 
A
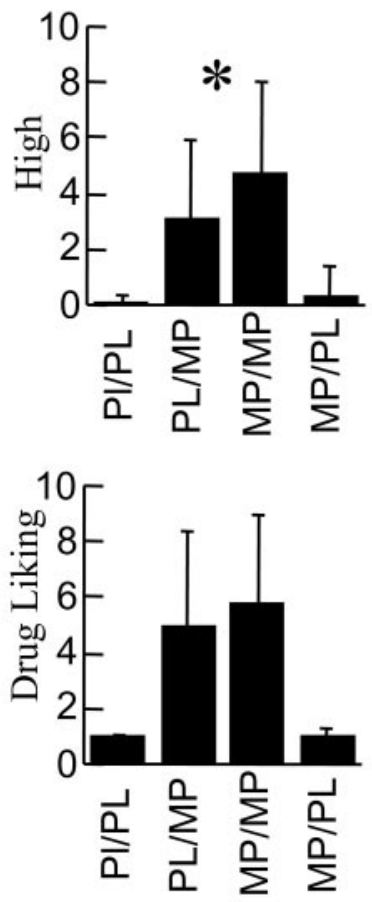
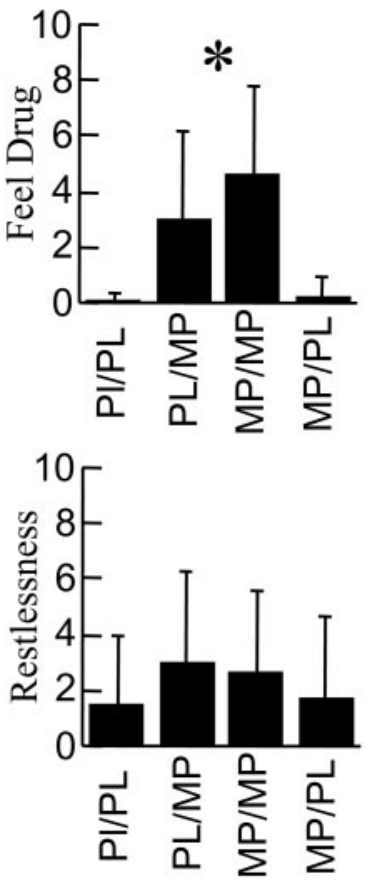

Expected placebo received MP (PL/MP)

B

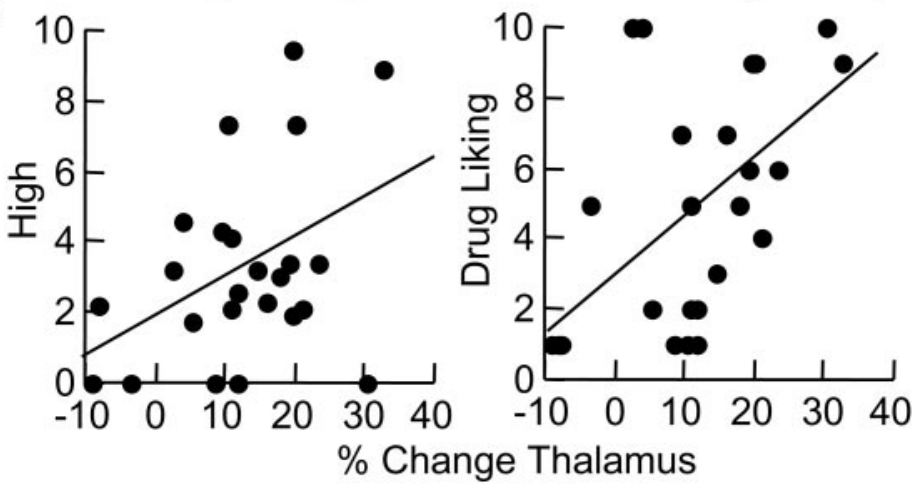

Expected MP received MP (MP/MP)

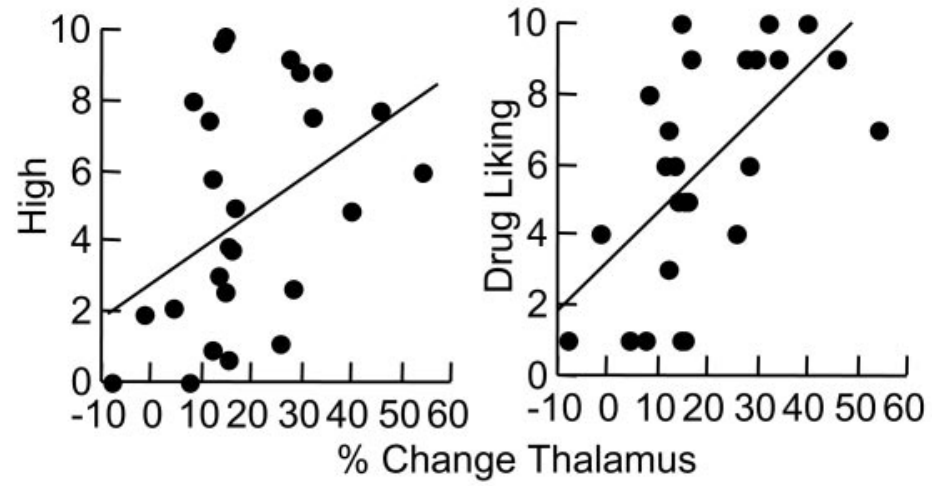

Figure 5. A, Self-reports of drug effects. MP (unexpected and expected) significantly increased self-report of high (repeated measures ANOVA; $F=32 ; p<0.0001)$, drug liking $(F=34 ; p<$ $0.0001)$, feel drug $(F=26 ; p<0.0001)$, and restlessness $(F=4 ; p<0.05)$. Asterisk indicates significant differences $(p<0.05)$ between MP when unexpected (PL/MP) versus when expected (MP/MP). B, Correlations between the changes in metabolism in thalamus and the increases in self-reports of high and drug liking after unexpected and expected MP.

For this study subjects were asked specifically to refrain from moving. Thus MP-induced relative decreases in motor cortex, an effect that has been documented previously by others (Devous et al., 2001), is likely to reflect the inhibitory control that subjects had to exert so that they did not move during the imaging procedure.

\section{Effects of expectation on MP-induced changes in regional} brain metabolism

When the subjects expected to receive MP and did (MP/MP), they had a significantly more intense and greater area of activation in cerebellum (vermis) and in thalamus than when they were not expecting it (PL/MP).

We hypothesized that expectation would enhance the pharmacological effects of MP, which amplifies DA and NE signals via blockade of DAT and norepinephrine transporters. Although we did not measure DA and NE changes in response to MP, the fact that the pattern of metabolic and behavioral effects induced by MP was similar although larger for expected than unexpected MP supports this hypothesis. Indeed, the notion that expectation can emulate the drug-induced brain effects may provide a neural basis for a "placebo" effect. For example, this was documented in a study of Parkinson's disease when a placebo resulted in DA increases that were equivalent to those induced by a DA agonist drug (de la Fuente-Fernandez et al., 2001).

The enhanced activation of the thalamus when MP was expected (compared with unexpected MP) identifies this as a brain region involved with expectation effects in the response to the drug. This finding is consistent with that of a recent study in nonhuman primates, which showed that the largest difference between contingent versus noncontingent administration of cocaine were the increases in thalamic metabolism (Porrino et al., 2002). Metabolic activity in thalamus was also found to differ when rats received cocaine in a conditioned environment versus their home cage (Knapp et al., 2002). Using imaging we also reported that MP increased DA in thalamus in cocaine abusers but not in controls, which we postulated reflected a conditioned response from previous drug exposure (Volkow et al., 1997c). Thus the current findings provide further evidence in humans of thalamic involvement in conditioned reinforced responses (McAlonan et al., 1993). The ventral striatum is known to play a role in expectation (Cromwell and Schultz, 2003), and failure to document an effect in this study is likely to reflect the limited temporal resolution of PET-FDG. On the other hand, the fact that an expectation effect was observed in thalamus with a $30 \mathrm{~min}$ measurement suggests that thalamic involvement may be more sustained than that of other brain regions.

The significant association between MP-induced increases in thalamic metabolism and self reports of high and drug liking suggests that it may modulate the reinforcing effects of MP. Indeed, the thalamus (mediodorsal nucleus) is neuroanatomically well situated to modulate reinforcing responses because it receives DA projections (Groenewegen, 1988) and is a relay between NAc and OFC (Nauta, 1971); however, correlations do not necessarily imply causal relationships, and more studies are required to establish whether the thalamus is involved with drug reinforcement.

The cerebellar vermis was the other region that differed be- 
tween expected and unexpected MP. Unlike thalamic activation, however, the changes in vermis were not associated with the reinforcing effects of MP. Thus it is likely that the cerebellar response may reflect conditioned responses that are not linked with effects that are consciously perceived as rewarding. Animal studies have consistently documented the involvement of the cerebellum (including vermis) in conditioned responses (Supple and Leaton, 1990; Ghelarducci and Sebastiani, 1997; Fischer et al., 2000) and expectancy (Courtemanche et al., 2002). Imaging studies have reported cerebellar activation when cocaine abusers are exposed to cocaine cues, which also reflect a conditioned response (Grant et al., 1996).

It is notable that the opposite pattern was observed in left lateral OFC, where unexpected MP produced greater increases than expected MP. This effect is consistent with the recent literature on the impact of unexpected rewards on OFC (Schultz et al., 2000; Berns et al., 2001). In this study we were unable to show greater activation of OFC by expectation alone, which we reasoned was attributable to the poor temporal resolution of PET-FDG.

These results replicate previous findings showing that the reinforcing effects of drugs of abuse are greater when they are expected than when they are not (Kirk et al., 1998). The extent to which expectation affects natural reinforcers differently from drugs of abuse merits further investigation.

\section{Study limitations}

Brain metabolic responses measured with PET-FDG reflect activity occurring over $30 \mathrm{~min}$. Thus the short-lived duration of some of the behavioral effects were likely lost amid the metabolic responses. fMRI would have provided a better assessment of time course for the various drug effects; however, PET has the advantage of providing a measure that reflects absolute changes in activity.

Here we used MP instead of cocaine because its longer pharmacokinetics properties were advantageous for PET-FDG studies. However, subjects were told that the effects of MP would be very similar to those of cocaine, so it is possible that the effects of expectation may have been even stronger if they expected cocaine.

Metabolic measures are indirect measures of drug effects, and thus we cannot determine the extent to which the effects of expectation reflect an amplification of the effects of MP on DA and NE.

\section{Summary}

This study provides evidence that reinforcing effects of drugs of abuse are not just a function of their pharmacological effects but also of expectation of their effects. We documented an enhancement of MP-induced increases in thalamic and cerebellar metabolism and in its reinforcing effects when MP was expected versus when it was not. The thalamic activation with MP was associated with the subjective experience of high and drug liking, suggesting that it reflects the expectation-induced enhancement of its reinforcing effects. A different pattern was documented for metabolic changes in OFC, which showed larger increases when MP was not expected than when it was expected, corroborating its role in unexpected reward.

\section{References}

Bendriem B, Dewey SL, Schlyer DJ, Wolf AP, Volkow ND (1991) Quantitation of the human basal ganglia with positron emission tomography: a phantom study of the effect of contrast and axial positioning. IEEE Trans Med Imaging 10:216-222.
Berns GS, McClure SM, Pagnoni G, Montague PR (2001) Predictability modulates human brain response to reward. J Neurosci 21:2793-2798.

Breiter HC, Gollub RL, Weisskoff RM, Kennedy DN, Makris N, Berke JD, Goodman JM, Kantor HL, Gastfriend DR, Riorden JP, Mathew RT, Rosen BR, Hyman SE (1997) Acute effects of cocaine on human brain activity and emotion. Neuron 19:591-611.

Courtemanche R, Pellerin JP, Lamarre Y (2002) Local field potential oscillations in primate cerebellar cortex: modulation during active and passive expectancy. J Neurophysiol 88:771-782.

Cromwell HC, Schultz W (2003) Effects of expectations for different reward magnitudes on neuronal activity in primate striatum. J Neurophysiol 89:2823-2838.

de la Fuente-Fernandez R, Ruth TJ, Sossi V, Schulzer M, Calne DB, Stoessl AJ (2001) Expectation and dopamine release: mechanism of the placebo effect in Parkinson's disease. Science 293:1164-1166.

Devous Sr MD, Trivedi MH, Rush AJ (2001) Regional cerebral blood flow response to oral amphetamine challenge in healthy volunteers. J Nucl Med 42:535-542.

Di Chiara GD, Imperato A (1988) Drugs abused by humans preferentially increase synaptic dopamine concentrations in the mesolimbic system of freely moving rats. Proc Natl Acad Sci USA 85:5274-5278.

Dirckx, SG, Risinger RC, Ross TJ, Li Z, Li SJ, Stein EA 2003 Comparing iv methylphenidate and cocaine in the human brain using fMRI. 9th International Conference on Functional Mapping of the Human Brain, New York, June.

Duvauchelle CL, Ikegami A, Asami S, Robens J, Kressin K, Castaneda E (2000) Effects of cocaine context on NAcc dopamine and behavioral activity after repeated intravenous cocaine administration. Brain Res 862:49-58.

Efron B (1982) The jackknife, the bootstrap, and other resampling plans. Philadelphia: Society for Industrial and Applied Mathematics.

Fischer H, Andersson JL, Furmark T, Fredrikson M (2000) Fear conditioning and brain activity: a positron emission tomography study in humans. Behav Neurosci 114:671-680.

Fischman MW, Foltin RW (1991) Utility of subjective-effects measurements in assessing abuse liability of drugs in humans. Br J Addict 86:1563-1570.

Friston KJ, Holmes AP, Worsley K, Poline JB, Frith CD, Frackowiak RSJ (1995) Statistical parametric maps in functional brain imaging: a general linear approach. Hum Brain Mapp 2:189-210.

Ghelarducci B, Sebastiani L (1997) Classical heart rate conditioning and affective behavior: the role of the cerebellar vermis. Arch Ital Biol 135:369-384.

Graham J, Porrino LJ (1995) Neuroanatomical substrates of cocaine selfadministration. In: Neurobiology of cocaine (Hammer R, ed), pp 3-14. Boca Raton, FL: CRC.

Grant S, London ED, Newlin DB, Villemagne VL, Liu X, Contoreggi C, Phillips RL, Kimes AS, Margolin A (1996) Activation of memory circuits during cue-elicited cocaine craving. Proc Natl Acad Sci USA 93:12040-12045.

Groenewegen HJ (1988) Organization of the afferent connections of the mediodorsal thalamic nucleus in the rat, related to the mediodorsalprefrontal topography. Neuroscience 24:379-431.

Hemby SE, Co C, Koves TR, Smith JE, Dworkin SI (1997) Differences in extracellular dopamine concentrations in the nucleus accumbens during response-dependent and response-independent cocaine administration in the rat. Psychopharmacology (Berl) 133:7-16.

Hook JC, Wise SP (1995) Distributed modular architecture linking basal ganglia, cerebellum and cerebral cortex: their role in planning and controlling action. Cereb Cortex 2:95-110.

Kirk JM, Doty P, De Wit H (1998) Effects of expectancies on subjective responses to oral delta 9-tetrahydrocannabinol. Pharmacol Biochem Behav 59:287-293.

Knapp CM, Printseva B, Cottam N, Kornetsky C (2002) Effects of cue exposure on brain glucose utilization 8 days after repeated cocaine administration. Brain Res 950:119-126.

Lancaster JL, Woldorff MG, Parsons LM, Liotti M, Freitas CS, Rainy L, Kochunov PV, Nickerson D, Mikiten SA, Fox PT (2000) Automated Talairach atlas labels for functional brain mapping. Hum Brain Mapp 10:120-131.

London ED, Cascella NG, Wong DF, Phillips RL, Dannals RF, Links JM, Herning R, Grayson R, Jaffe JH, Wagner HN Jr (1990) Cocaine-induced 
reduction of glucose utilization in human brain. A study using positron emission tomography and [fluorine18]-fluorodeoxyglucose. Arch Gen Psychiatry 47:567-574.

McAlonan GM, Robbins TW, Everitt BJ (1993) Effects of medial dorsal thalamic and ventral pallidal lesions on the acquisition of a conditioned place preference: further evidence for the involvement of the ventral striatopallidal system in reward-related processes. Neuroscience 52:605-620.

Melchitzky DS, Lewis DA (2000) Tyrosine hydroxylase- and dopamine transporter-immunoreactive axons in the primate cerebellum. Evidence for a lobular- and laminar-specific dopamine innervation. Neuropsychopharmacology 22:466-472.

Miller RG (1974) The jackknife-a review. Biometrika 61:1-15.

Mitchell SH, Laurent CL, de Wit H (1996) Interaction of expectancy and the pharmacological effects of d-amphetamine: subjective effects and selfadministration. Psychopharmacology (Berl) 125:371-378.

Nauta WJH (1971) The problem of the frontal lobe: a reinterpretation. J Psychiatric Res 8:167-189.

Patrick KS, Caldwell RW, Ferris RM, Breese GR (1987) Pharmacology of the enantiomers of threo-methylphenidate. J Pharmacol Exp Ther 241:152-158.

Porrino LJ, Lyons D, Miller MD, Smith HR, Friedman DP, Daunais JB, Nader MA (2002) Metabolic mapping of the effects of cocaine during the initial phases of self-administration in the nonhuman primate. J Neurosci 22:7687-7694.

Quenouille MH (1956) Notes on bias in estimation. Biometrika 43:353-360.

Rademacher J, Morosan P, Schormann T, Schleicher A, Werner C, Freund HJ, Zilles K (2001) Probabilistic mapping and volume measurement of human primary auditory cortex. NeuroImage 13:669-683.

Reznikoff GA, Manaker S, Rhodes CH, Winokur A, Rainbow TC (1986) Localization and quantification of beta-adrenergic receptors in human brain. Neurology 36:1067-1073.

Robinson TE, Berridge KC (1993) The neural basis of drug craving: an incentive-sensitization theory of addiction. Brain Res Rev 18:247-291.

Schultz W, Tremblay L, Hollerman JR (1998) Reward prediction in primate basal ganglia and frontal cortex. Neuropharmacology 37:421-429.

Schultz W, Tremblay L, Hollerman JR (2000) Reward processing in primate orbitofrontal cortex and basal ganglia. Cereb Cortex 10:272-284.

Schwartz WJ, Smith CB, Davidsen L, Savaki H, Sokoloff L, Mata M, Fink DJ, Gainer H (1979) Metabolic mapping of functional activity in the hypothalamo-neurohypophysial system of the rat. Science 205:723-725.

Sokoloff L, Reivich M, Kennedy C, Des Rosiers MH, Patlak CS, Pettigrew KD, Sakurada O, Shinohara M (1977) The ${ }^{14} \mathrm{C}$-deoxyglucose method for the measurement of local cerebral glucose utilization: theory, procedure and normal values in the conscious and anesthetized albino rat. J Neurochem 28:897-916.

Srinivas NR, Hubbard JW, Quinn D, Korchinski ED, Midha K (1991) Extensive and enantioselective presystemic metabolism of DL-threomethylphenidate in humans. Prog Neuropsychopharmacol Biol Psychiat 15:213-220.

Supple Jr WF, Leaton RN (1990) Lesions of the cerebellar vermis and cerebellar hemispheres: effects on heart rate conditioning in rats. Behav Neurosci 104:934-947.

Volkow ND, Ding Y-S, Fowler JS, Wang GJ, Logan J, Gatley JS, Dewey SL, Ashby C, Lieberman J, Hitzemann R, Wolf AP (1995) Is methylphenidate like cocaine? Studies on their pharmacokinetics and distribution in human brain. Arch Gen Psychiatry 52:456-463.

Volkow ND, Wang G-J, Gatley SJ, Fowler JS, Ding Y-S, Hitzemann R, Logan J, Wong C, Lieberman J (1996) Temporal relationships between the pharmacokinetics of methylphenidate in the human brain and its behavioral and cardiovascular effects. Psychopharmacology 123:26-33.

Volkow ND, Wang G-J, Fowler JS, Logan J, Angrist B, Hitzemann RJ, Lieberman J, Pappas NS (1997a) Effects of methylphenidate on regional brain glucose metabolism in humans: relationship to dopamine D2 receptors. Am J Psychiatry 154:50-55.

Volkow ND, Rosen B, Farde L (1997b) Imaging the living human brain: magnetic resonance imaging and positron emission tomography. Proc Natl Acad Sci USA 94:2787-2788.

Volkow ND, Wang G-J, Fowler JS, Logan J, Gatley SJ, Hitzemann R, Chen AD, Dewey SL, Pappas N (1997c) Decreased striatal dopaminergic responsiveness in detoxified cocaine-dependent subjects. Nature 386:830-833.

Volkow ND, Wang G-J, Fowler JS, Fischman M, Foltin R, Abumrad NN, Gatley SJ, Logan J, Wong C, Gifford A, Ding Y-S, Hitzemann R, Pappas N (1999a) Methylphenidate and cocaine have a similar in vivo potency to block dopamine transporters in the human brain. Life Sci 65:7-12.

Volkow ND, Wang G-J, Fowler JS, Hitzemann R, Angrist B, Gatley SJ, Logan J, Ding Y-S, Pappas N (1999b) Association of methylphenidate-induced craving with changes in right striato-orbitofrontal metabolism in cocaine abusers: implications in addiction. Am J Psychiatry 156:19-26.

Wang G-J, Volkow ND, Roque CT, Cestaro VL, Hitzemann RJ, Cantos EL, Levy AV, Dhawan AP (1992) Functional significance of ventricular enlargement and cortical atrophy in normals and alcoholics as assessed by PET, MRI and neuropsychological testing. Radiology 186:59-65.

Wang G-J, Volkow ND, Hitzemann RJ, Wong C, Angrist B, Burr G, Pascani K, Pappas N, Lu A, Cooper T, Lieberman JA (1997) Behavioral and cardiovascular effects of intravenous methylphenidate in normal subjects and cocaine abusers. Eur Addiction Res 3:49-54. 